\title{
Research on fatigue assessment of the Flange Bolts Connection of Wind Turbine based on Finite Element Analysis
}

\author{
Jianping Liu ${ }^{1 \mathrm{a}}$, Yanhui $\mathrm{Ma}^{1}$, Junping $\mathrm{Chen}^{1}$, Changguo $\mathrm{Ji}^{1}$, Derui $\mathrm{Su}^{1}$ \\ ${ }^{1}$ Department of Electrical Engineering and Automation, Luoyang Institute of Science and \\ Technology, Luoyang, 471023, China \\ aemail: liujianping1415@163.com
}

Keywords: fatigue assessment; bolt; Wind Turbine; Finite Element Analysis

\begin{abstract}
Wind energy as an inexhaustible green energy is the development trend of the future. Wind turbine bolts play an important role for the service safety of wind turbine, and have become the new promising product of the fastener industry in the world. But because of the high strength bolt connection failure caused by a tower pour accident, caused the attention of the scientific research workers, and put forward to improve reliability, high strength bolt connection to ensure that the wind turbine operation research problems. The rigid strength, toughness and hardenability requirements of the wind turbine bolt steels are really challenging work. Based on the fatigue life model, the calculation method of the fatigue reliability index of high strength bolt in the grid structure with bolt-sphere joints is discussed and some important parameters are gained.
\end{abstract}

\section{Introduction}

In the recent years, the non renewable energy is continuously consumed, so that all countries try their best to develop wind energy technology. Our country is rich in wind energy resources, so the development and utilization of wind energy resources and the development of wind power industry have become an inevitable trend to solve the increasingly serious energy crisis. However, with the installation of a large number of wind power units, a series of safety failure problems are also exposed. The connection of each part of the wind turbine is made of high strength bolt, the connection quality of the bolt can be affected by bolt quality and installation method, ultimately the safety and reliability of the whole wind turbine can be affected. The wind power system is usually working under the action of alternating loads, the high strength bolt is always in the state of fatigue stress. So the evaluation of the fatigue performance of the dynamic load bolt is essential. However, the fatigue failure of the bolts is very difficult to find in preliminary stage. Therefore, in order to prevent the failure of the wind power system, it is important to study the fatigue failure of high strength bolts.

Based on the above research background and the above application background, this paper uses the axial pull-fatigue way which similar to actual working condition and through the comparison of two kinds of bolt is used and not used method to determine the hub connected bolt the blade bolt fatigue performance. Bolted ring-flanges are widely used in support structures for offshore wind turbines for the connection between tower segments or between tower and sub-structures such as jackets, tripods or even floating structures. Moreover, ring-flange connections may also be applied as alternative to grouted joints for the conjunction between transition piece and monopile foundations, cf. Fig.1. For this application until today grouted joints, which are established by filling the annulus between monopole and slightly larger transition piece with a high-strength grout material, are the predominately used design solution. This connection, well established in the oil and gas sector to attach offshore platforms to driven pile foundations, allows to compensate inclinations from the ramming process of the pile. However, recently reported settlements of grouted joints on monopiles have revealed that existing experiences obtained from the oil and gas sector may not unconditionally be transferred to applications for offshore wind turbines. As a consequence, several wind farm projects with monopile foundation, e.g. the offshore wind park “Amrumbank West" in the German North Sea, are now planned and under construction with a 
design concept with bolted ringflanges instead of grouted joints, cf. Gollub at al. (2014).

Bolts in wind turbines are subjected to high cyclic loads with considerable numbers of load cycles and variable amplitudes. Due to the high notch effect of the thread, bolts are decidedly susceptible to fatigue damage. Thus, it is essential that bolts in ring-flange connections are preloaded with high forces in order to reduce fatigue loads on the bolts. For protection against corrosion the bolts are commonly hot-dip galvanized. The zinc coating, however, affects the fatigue strength of the bolts.

Ring-flange connections in wind turbines are usually executed with prestressed, high-strength bolt assemblies (HV-sets) with large diameters of M36 and bigger. The magnitude of the acting loads at the bottom of the tower of large and powerful offshore turbines usually requires the application of very large bolt diameters M64 or M72. This applies even more for the connection level at the bottom of the transition piece on a monopile. In constructional engineering the application of such bolt dimension takes place almost exclusively in the emerging wind energy sector. Consequently, even though applicable design standards do not explicitly exclude their application on larger diameters, the experimental validation of relevant fatigue properties is mostly limited to smaller dimensions.

\section{Theoretical model analysis}

(1)Low-cycle fatigue

Where the stress is high enough for plastic deformation to occur, the accounting of the loading in terms of stress is less useful and the strain in the material offers a simpler and more accurate description. Low-cycle fatigue is usually characterised by the Coffin-Manson relation (published independently by L. F. Coffin in 1954 and S. S. Manson 1953):

$$
\frac{\Delta \varepsilon_{p}}{2}=\varepsilon_{f}^{\prime}(2 N)^{c}
$$

where,

$\Delta \varepsilon p / 2$ is the plastic strain amplitude;

ef' is an empirical constant known as the fatigue ductility coefficient, the failure strain for a single reversal;

$2 \mathrm{~N}$ is the number of reversals to failure ( $\mathrm{N}$ cycles);

$\mathrm{c}$ is an empirical constant known as the fatigue ductility exponent, commonly ranging from -0.5 to -0.7 for metals in time independent fatigue. Slopes can be considerably steeper in the presence of creep or environmental interactions.

A similar relationship for materials such as Zirconium, is used in the nuclear industry

(2) Paris' Law

Typical fatigue crack growth rate graph

In Fracture mechanics, Anderson, Gomez and Paris derived relationships for the stage II crack growth with cycles $\mathrm{N}$, in terms of the cyclical component $\Delta \mathrm{K}$ of the Stress Intensity Factor $\mathrm{K}[13]$

$$
\frac{\mathrm{d} a}{\mathrm{~d} N}=C(\Delta K)^{m}
$$

where $a$ is the crack length and $m$ is typically in the range 3 to 5 (for metals).

This relationship was later modified (by Forman, 1967[14]) to make better allowance for the mean stress, by introducing a factor depending on $(1-\mathrm{R})$ where $\mathrm{R}=\min$ stress/max stress, in the denominator.

(3) Miner's Rule

In 1945, M A Miner popularised a rule that had first been proposed by A. Palmgren in 1924. The rule, variously called Miner's rule or the Palmgren-Miner linear damage hypothesis, states that where there are k different stress magnitudes in a spectrum, $\mathrm{Si}(1 \leq \mathrm{i} \leq \mathrm{k})$, each contributing ni(Si) cycles, then if $\mathrm{Ni}(\mathrm{Si})$ is the number of cycles to failure of a constant stress reversal $\mathrm{Si}$, failure occurs when:

$$
\sum_{i=1}^{k} \frac{n_{i}}{N_{i}}=C
$$


$\mathrm{C}$ is experimentally found to be between 0.7 and 2.2. Usually for design purposes, $\mathrm{C}$ is assumed to be 1 . This can be thought of as assessing what proportion of life is consumed by a linear combination of stress reversals at varying magnitudes.

Though Miner's rule is a useful approximation in many circumstances, it has several major limitations:

It fails to recognise the probabilistic nature of fatigue and there is no simple way to relate life predicted by the rule with the characteristics of a probability distribution. Industry analysts often use design curves, adjusted to account for scatter, to calculate $\mathrm{Ni}(\mathrm{Si})$.

There is sometimes an effect in the order in which the reversals occur. In some circumstances, cycles of low stress followed by high stress cause more damage than would be predicted by the rule. It does not consider the effect of an overload or high stress which may result in a compressive residual stress that may retard crack growth. High stress followed by low stress may have less damage due to the presence of compressive residual stress.

\section{Detailed theoretical calculation and analysis}

(1)build the finite element model

As the requirement, the CAD model was built as follows:

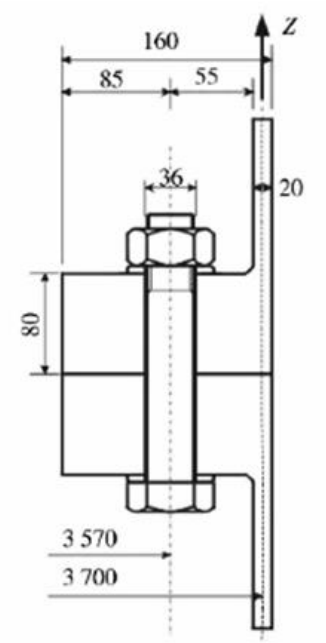

Fig 1 CAD model of bolt

And the finite element model is as follows:

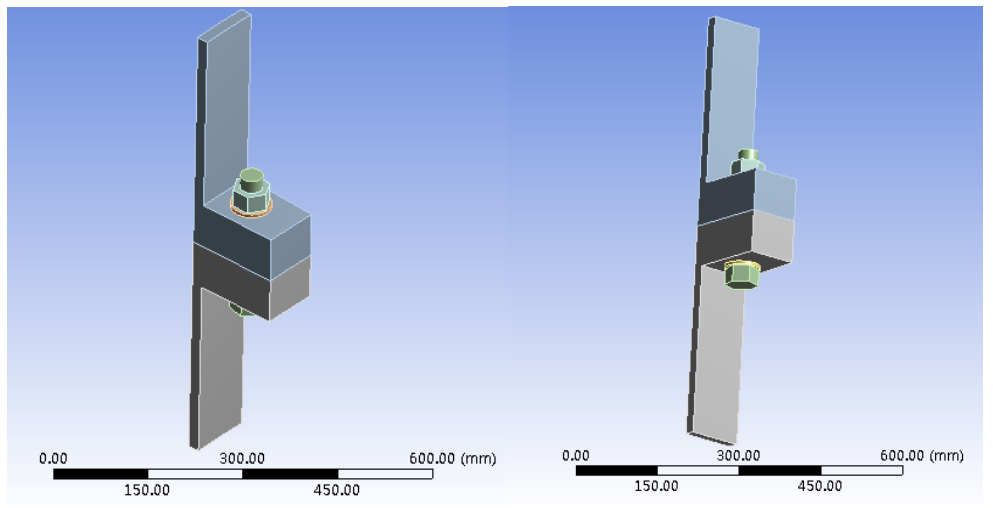

Fig 2. the finite element model

The geometrical parameters as shown in Figure 1, the other parameters are as follows: high strength bolts of grade 10.9, M36 * 226 specifications, the preload of FV $=510 \mathrm{kN} \mathrm{DH}=39 \mathrm{~mm}$, bolt, gasket gasket inner diameter Daw $=66 \mathrm{~mm}$, DIW $=37 \mathrm{~mm} \mathrm{TW}=6 \mathrm{~mm}$, the thickness of the gasket, the number of bolts $n=112$.

The model includes the upper flange and the lower flange, bolts, nuts, washers and part of the tower wall. Each component materials are high strength low alloy structural steel, elastic modulus is $2.06 * 106 \mathrm{MPa}$, the Poisson's ratio of 0.3 , the density of $7.85 * 103 \mathrm{~kg} / \mathrm{m} 3$. 
Flange connection model as shown in Figure 2, flange contact finite element model as shown in figure 3.

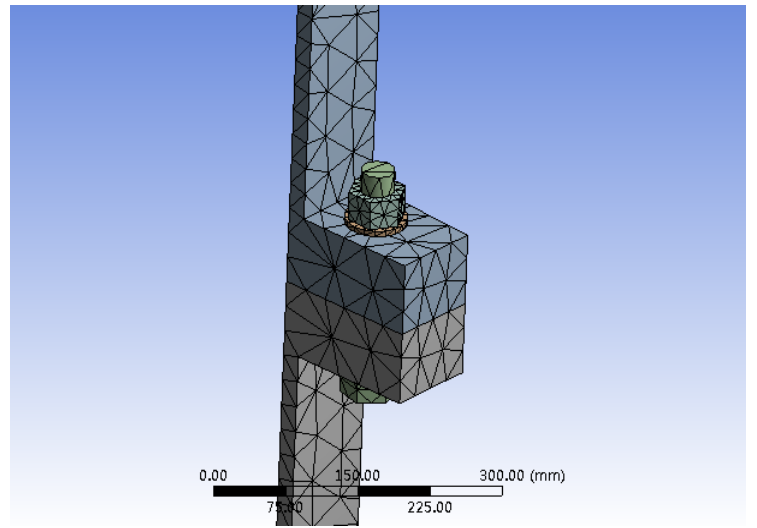

Fig 3. connection model

The contact relation between the contact settings: nuts and washers and bolts arranged in contact is rigid and the upper and lower flange contact set to contact friction, gasket and flange contact set to friction and friction coefficient on the contact between the 0.15 .

(2)Fatigue analysis
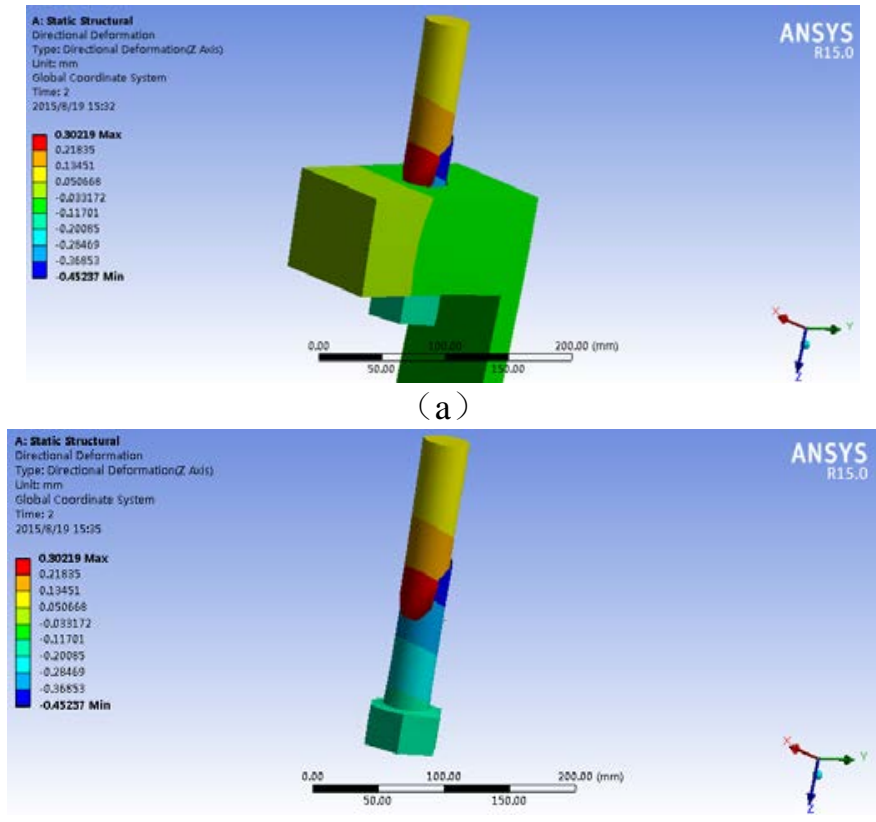

(b)

Fig.4 along the $\mathrm{Z}$ direction (axis) deformation results

Figure 8 is the $\mathrm{Z}$ direction (axis) deformation results. It can be seen that the deformation of bolt along the axial direction of the present end tension and compression deformation at one end. The contact surface of the screw in the two parts of the left flange, the maximum deformation of the screw was $0.30219 \mathrm{~mm}$, and the screw on the right side of deformation is $-0.45237 \mathrm{~mm}$. It can be seen that the contact surface of the screw part in two flange, the maximum deformation of the screw.

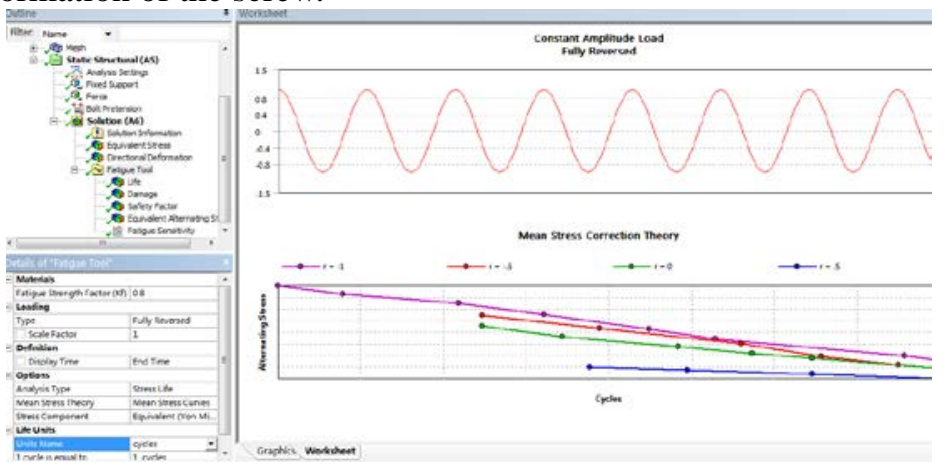

Fig.5 fatigue tool setting result 


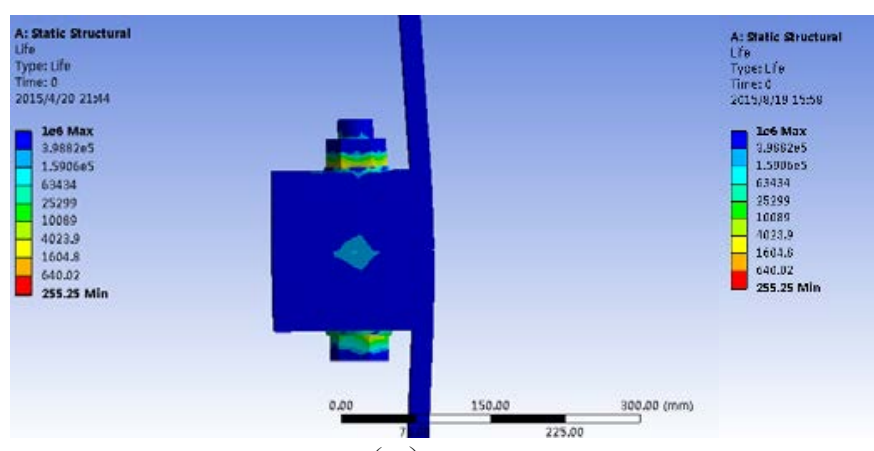

(a)

Fig.6 fatigue life nephogram

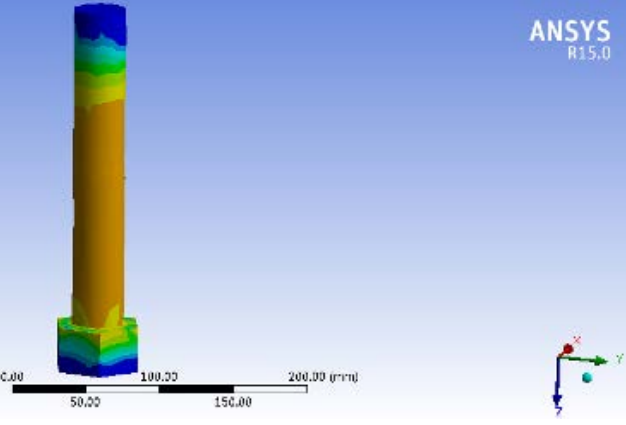

(b)

Figure 6 shows the fatigue life nephogram bolt connection. Contour display due to fatigue cycles until failure. It can be seen that the fatigue life of small bolt central region, and the fatigue life of both ends of the relatively large.

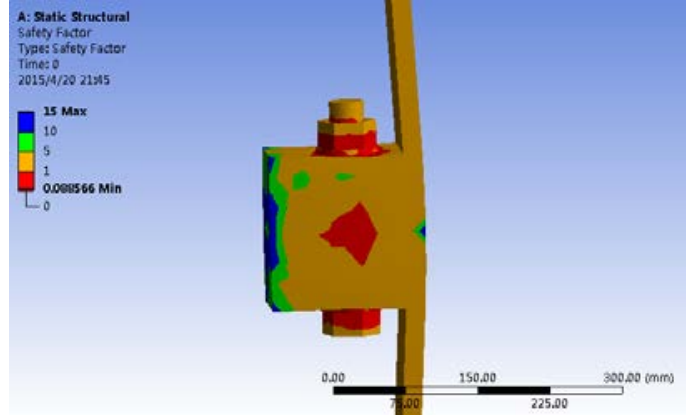

(a)

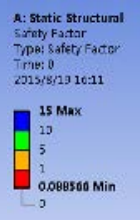

Fig.7 the fatigue safety factor nephogram

Figure 7 is the bolt fatigue safety factor nephogram. The safety coefficient isoline is about a given design life under failure. It can be seen that the fatigue safety coefficient of the central region of the small bolt.

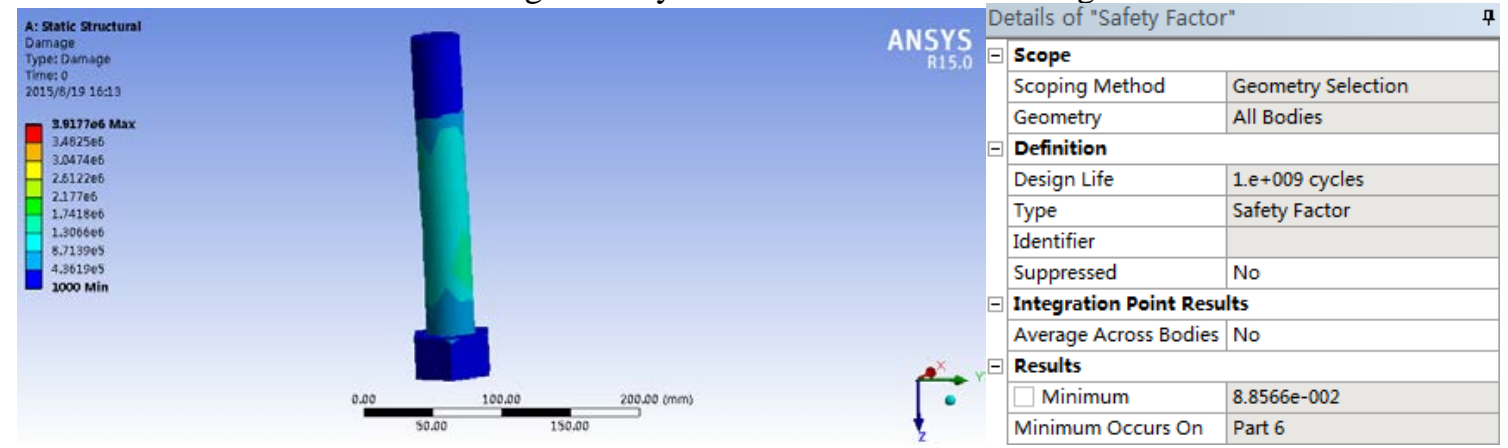

Fig.8 Figure destruction
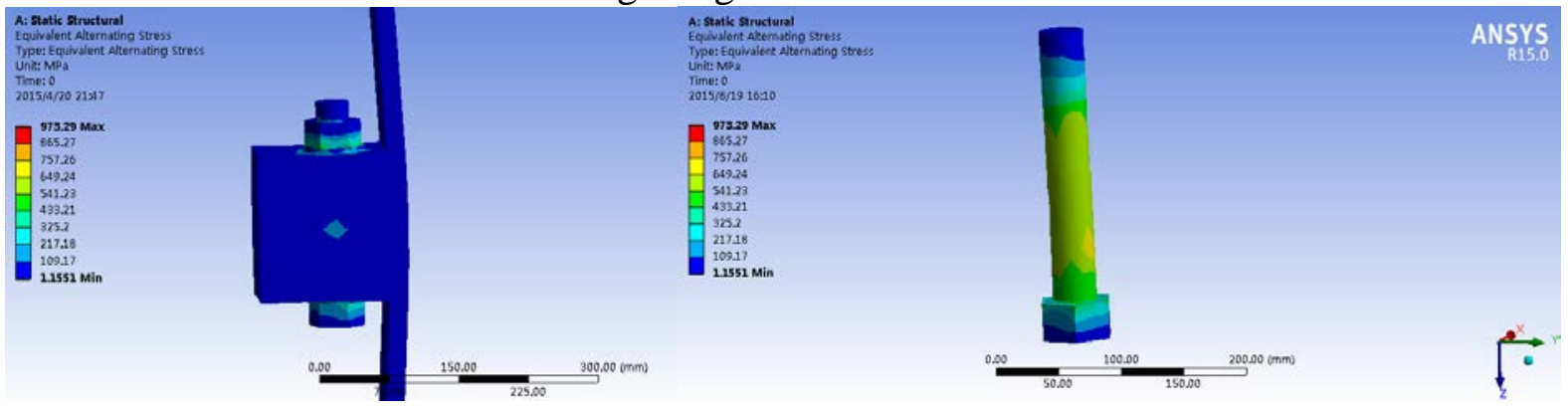

Fig.9 equivalent alternating stress nephogram

Figure 9 is the equivalent stress nephogram of alternating bolt connection. It can be seen that the central region of the bolt equivalent alternating stress is large, about 500 700MPa. 


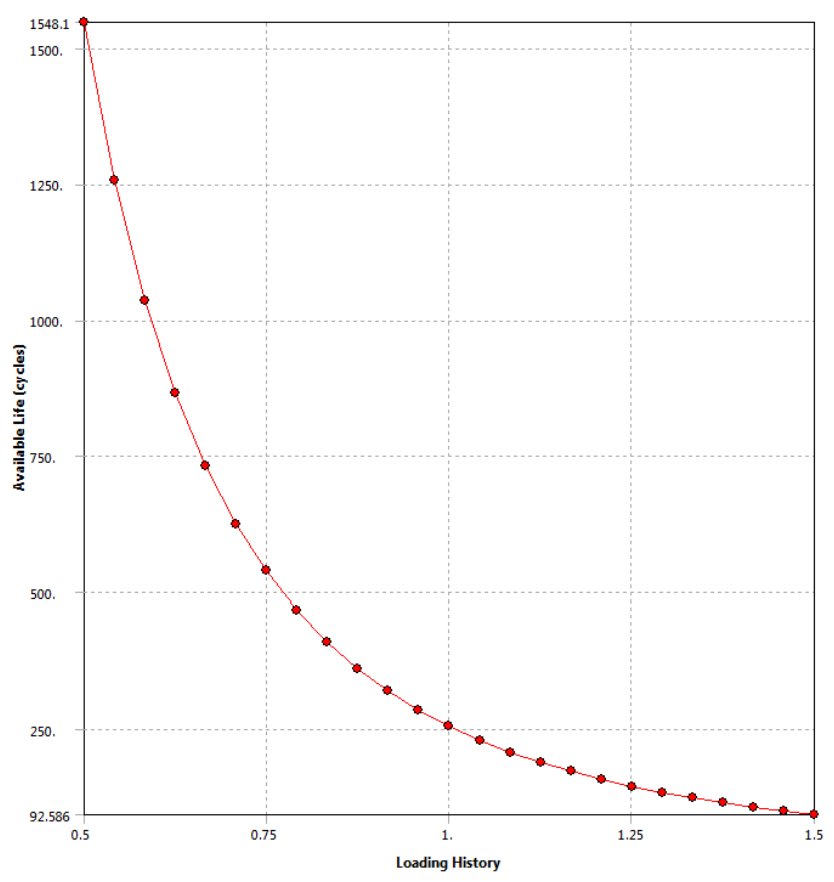

Figure 10 fatigue sensitive curve

Figure 10 shows the curve of fatigue sensitive bolt connection.

\section{Conclusions}

Based on the analysis of this paper, damage originated in high stress, high local strain; Figure 16 along the $\mathrm{Z}$ direction (axis) deformation results. It can be seen that the deformation of bolt along the axial direction of the present end tension and compression deformation at one end. The contact surface of the screw in the two parts of the left flange, the maximum deformation of the screw was $0.30219 \mathrm{~mm}$, and the screw on the right side of deformation is $-0.45237 \mathrm{~mm}$. It can be seen that the contact surface of the screw part in two flange, the maximum deformation of the screw. So the dangerous parts of the site is fatigue failure.

\section{References}

[1] Sutherland. H. Fatigue Analysis of Wind Turbine[J]. Sandia National Labs, 2009, SAND9 9-0089.

[2] Andersen.S.I, Lilholt.H, Lystrup. A. Fatigue properties and design of wing blades for wind turbines[R], Risoe National Lab, Materials Dept NEI-DK-1666.

[3] Musial. Walt, Allread.Jack. Test methodology and control of full-scale fatigue tests on wind turbine blades[J]. American Society of Mechanical Engineers. 1993,14:199-206

[4] Liu Wenguang, Chen Guoping. Vibration and fatigue coupling analysis of a cantilever beam with a crack [J]. vibration and shock, 2011,30 (5):140-144

[5] Liu Wenguang. Structural resonance fatigue test and vibration fatigue coupling analysis of crack member [D]. Nanjing University of Aeronautics \& Astronautics, 2010 